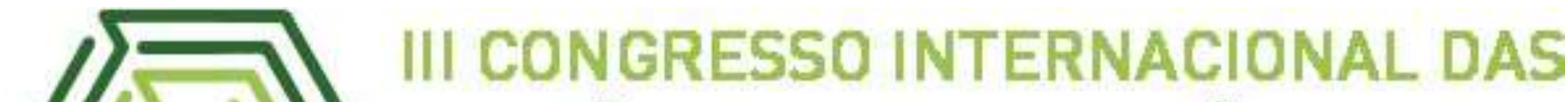 CIÊNCIAS AGRÁRIAS COINTER - PDVAGRO 2018
}

\section{EFEITO DA MARINAÇÃO COM PRÓPOLIS VERDE NAS CARACTERÍSTICAS FÍSICAS DA CARNE DE FRANGO}

\section{EFFECT OF MARINATION WITH GREEN PROPOLIS ON THE PHYSICAL CHARACTERISTICS OF CHICKEN MEAT}

\author{
Apresentação: Pôster \\ DOI: https://doi.org/10.31692/2526-7701.IIICOINTERPDVAGRO.2018.00444
}

\section{Introdução}

O comércio brasileiro de carne de frangos se expande a cada ano, formando uma cadeia produtiva que envolve plantio de grãos, alojamento de matrizes e pintos, abatedouros, frigoríficos, transporte e distribuição, bem como ainda conta com desenvolvimento genético de aves. O desenvolvimento bem-sucedido dessa cadeia produtiva elevou a oferta de carne de frango a todas as camadas de renda da população brasileira (BARCELLOS, 2006).

A carne de frango fornece nutrientes necessários em dietas equilibradas. Proteínas, lipídios, vitaminas e minerais encontrados na composição da carne. A coloração da carne é variável de espécie para espécie e também está relacionada com a atividade física do animal. O componente que confere cor a carne é a mioglobina. Outros fatores que interfere na coloração da carne são a idade, sexo, alimentação e habitat do animal (VENTURINI et al., 2007).

Com isso, objetiva-se com o presente trabalho identificar alterações nas características físicas da carne de frango quando submetida a diferentes tempos de marinação com extrato etanolíco à $2 \%$ de própolis verde.

\section{Fundamentação Teórica}

A carne de frango é utilizada na alimentação, sendo classificada como alimento saudável, pobre em gorduras, desde que seja consumido sem pele. Essa carne apresenta rico teor de proteínas de boa qualidade e é recomendada consumo em todas as idades e podem ser consumidas, sem pele, por alguém que tenha riscos cardiovasculares, pois contém uma baixa taxa de colesterol (VENTURINI et al., 2007). 
Os marinados surgiram como alternativa de produto semi-preparado com tempo de conservação prolongado, ampliando as opções de consumo para carnes e aves. Podem ser designados como carnes, aves e peixes, cuja penetração ou difusão da salmoura, geralmente elaborada com vinagre e especiarias, ocasiona melhoria na textura e no sabor (PORTO et al, 2000).

A própolis se constitui numa série de substâncias resinosas, gomosas e balsâmicas, de consistência viscosa, possui aroma característico (balsâmico e resinoso), dependendo da origem botânica, cor variável desde a amarelada, esverdeada clara ao pardo escuro. Pode ter um sabor de suave balsâmico a forte, amargo e picante e a sua consistência varia do maleável à ligeiramente rígida, quando em temperatura ambiente, e rígida em temperaturas abaixo de $20^{\circ} \mathrm{C}$ (APACAME, 1999).

Como qualquer produto natural, há um numero de constituintes na própolis e sua extração é realizada da mesma forma como em outros alimentos, alguns deles também são conhecidos por ter atividade biológica, dessas substancias com atividade biológica, nenhuma contribuiu tanto para os efeitos observados da própolis como os flavonoides (LAPPE, 2004).

Mediante isso, a utilização da própolis verde na marinação de carnes com intuito de observar alterações físicas tem despertado o interesse de pesquisadores, isso devido as boas características biológicas desse produto natural.

\section{Metodologia}

O experimento foi realizado na Universidade Federal Rural do Semi-Árido (UFERSA) e as amostras de frango foram adquiridas em supermercados da cidade. Foram utilizados filés de peito que foram pesados e separados em três grupos, cada um com um tratamento específico: 0EEPVD10 (carne de frango sem marinação com extrato etanolico da própolis verde por dez minutos), 0EEPVD20 (carne de frango sem marinação com extrato etanolico da própolis verde por vinte minutos), 1EEPVD (carne de frango com marinação com extrato etanolico da própolis verde por dez minutos) e 2EEPVD (carne de frango com marinação com extrato etanolico da própolis verde por vinte minutos).

As analises físicas foram realizadas no Laboratório de Análises Instrumentais e Sensoriais (LANIS) da UFERSA. Os cortes foram imersos nos marinados utilizando os tempos de dez e vinte minutos para realização em seguida das análises físicas. Foram feitos testes de ph, cor, capacidade de retenção de água (CRA), perda de peso por cocção (PPC) e força de cisalhamento $(\mathrm{CF})$.

$\mathrm{O}$ pH foi determinado de acordo com a metodologia estabelecida pela AOAC (2005). Utilizou-se o pHmetro digital marca HANNA acoplado a um eletrodo de penetração. A CRA 
foi determinada baseando-se na medição de perda de água liberada, e por diferença foi determinado a CRA (Peso antes da pressão - Peso depois), expressa em porcentagem de peso perdido da amostra inicial.

Para a análise de PPC, realizou-se pesagem de três porções da carne. As amostras passaram por cocção através de um forno elétrico até atingirem temperatura $160^{\circ} \mathrm{C}$. E por diferença foi obtido resultado da percentagem da perda de água durante o processo de cocção. A FC foi realizada através do auxílio de um texturômetro de modelo (TEXTURE ANALYZER TAXT-125), acoplado ao dispositivo Warner-Bratzler (HDP/WBV) devidamente configurado para receber a amostra. Os resultados foram expressos em gramas, obtidos pelas médias de força máxima de ruptura das amostras.

A cor foi avaliada através de colorímetro Konica Minolta, CM-700d/600d (Sistema CIE $\mathrm{L}^{*} \mathrm{a}^{*} \mathrm{~b}^{*}$ ), cujo sistema considera as coordenadas $\mathrm{L}^{*}$ luminosidade (preto/branco), a* teor de vermelho (verde/vermelho) e b* teor de amarelo (azul/amarelo). Onde para definir a cor da carne são necessários três parâmetros: $\mathrm{L}^{*}$ : luminosidade ou claridade que varia de 0 (preto) a 100 (branco), $a^{*}$ : índice de vermelho, variando de $a^{*}>0$ (vermelho) a $a^{*<0}$ (verde) e $b^{*}$ : índice de amarelo, que varia de $\mathrm{b}^{*}>0$ (amarelo) $\mathrm{a} \mathrm{b}^{*}<0$ (azul). Foram realizadas três avaliações em três pontos distintos por amostra.

Os dados obtidos foram submetidos à análise de variância e teste de comparação de médias. Os efeitos dos diferentes tratamentos sobre cada variável foram comparados por meio do teste de Tukey, ao nível de 5\% de probabilidade, utilizando o SISVAR versão 5.6.

\section{Resultados e Discussões}

Os resultados das análises físicas das amostras estão descritos a seguir na tabela 1.

Tabela 1: Características físicas da carne de frango com adição ou não, de própolis verde com diferentes tempos de marinação. Fonte: Própria.

\begin{tabular}{llllllll}
\hline \multirow{2}{*}{ Tratamentos } & \multicolumn{7}{c}{ Parâmetros } \\
\cline { 2 - 8 } 0EEPVD10 & $\mathrm{pH}$ & $\mathrm{CRA}^{1}$ & $\mathrm{PPC}^{2}$ & $\mathrm{~L}^{*^{3}}$ & $\mathrm{a}^{*^{4}}$ & $\mathrm{~b}^{*^{5}}$ & $\mathrm{FC}^{6}$ \\
0EEPVD20 & 5,516 & 64,613 & $29,500 \mathrm{a}$ & 76,353 & 0,293 & 9,656 & 3,155 \\
1EEPVD & 5,506 & 59,973 & $24,966 \mathrm{ab}$ & 76,743 & 0,330 & 8,720 & 2,689 \\
2EEPVD & 5,613 & 61,843 & $16,830 \mathrm{~b}$ & 74,990 & 0,803 & 9,746 & 2,962 \\
\hline
\end{tabular}

\footnotetext{
${ }^{1}$ Capacidade de retenção de água; ${ }^{2}$ Perda de peso por cocção; ${ }^{3}$ Luminosidade; ${ }^{4}$ Coordenada verde- vermelho; ${ }^{5}$ Coordenada azul-amarelo; ${ }^{6}$ Força de cisalhamento. Médias na mesma coluna, seguidas de letras distintas diferem entre si pelo teste de Tukey, ao nível de 5\% de significância.
} 
A adição de própolis verde na carne de frango não apresentou resultados significativos entre os tratamentos, com exceção da PPC que foi reduzida nos tratamentos que continham própolis. A PPC é influenciada pela capacidade de retenção de água nas estruturas da carne, quanto maior a CRA menor a perda de peso durante a cocção, assim o tratamento com menor perda de peso de cocção foi o 1PVD.

Com relação a CRA, não houve resultados significativos nos tratamentos realizados, alguns fatores extrínsecos como as condições de criação do frango, temperatura, estresse calórico e densidade de criação podem afetar a capacidade de retenção de água (MENDES et al., 2011). A adição da própolis verde, em ambos tratamentos, reduziu a CRA quando comparamos com os valores do controle.

Características como a menor capacidade de retenção de água da carne de peito de frango correlacionam-se com o menor pH final (ALVES et al., 2016). A carne do peito de frango apresenta $\mathrm{pH}$ final variando de 5,70 até 5,96, embora o $\mathrm{pH}$ tenha se mantido estável em todos os tratamentos, seus valores estavam abaixo do que é recomendado na literatura.

As variáveis físicas analisadas para classificação do teor de luminosidade (L, a e b) não obtiveram significância nos seus resultados e se mantiveram estáveis em todos os tratamentos. A luminosidade da carne, por variar mais em função da umidade da carne, se mostrou elevada no presente trabalho indicando alta palidez (RODRIGUES et al., 2008). Em relação à cor, podese observar uma maior tendência para o tom amarelo demonstrado pelos valores superiores de $\mathrm{b}^{*}$ em relação ao $\mathrm{a}^{*}$, confirmando as características da musculatura do peito de aves (SOUZA

et al., 2004).

Os valores da FC ficaram abaixo de 5,5 a 5,8kgf/g descritos para peitos de frango desossados convencionalmente, com exceção apenas para o tratamento 1PVD, com isso é evidente que a maciez encontrada foi elevada (BRESSAN E BERAQUET, 2004), embora nas amostras dos tratamentos não foram observados resultados significativos.

\section{Conclusões}

A adição da própolis verde na carne de frango manteve as suas características físicas, sem causar danos a qualidade do produto, melhorando a sua PPC e garantido estabilidade nos demais parâmetros analisados, se tornando assim, uma possível fonte alternativa natural para conservar carne de frango.

\section{Referências}

ALVES, M. G. M.; ALBUQUERQUE, L. F.; BATISTA, A. S. M. Qualidade Da Carne De 
Frangos De Corte. Essentia, Sobral, v. 17, n. 2, p. 64-86, 2016.

APACAME - Associação Paulista de Apicultores Criadores de Abelhas Melíficas Européias. Regulamentos Técnicos para Fixação de Identidade e Qualidade de Própolis, Mensagem Doce, n. 52, p. 13-14, 1999.

BARCELLOS, O. Uma reflexão do comércio internacional dos setores de carne de frango e de soja do Brasil e Mercosul. Perspectiva econômica; v.2, n, 2: 15 - 36, jul./dez. 2006 issn $1808575 x$.

BRESSAN, M. C; BERAQUET, N. J. Tratamentos De Pré-Resfriamento E Resfriamento Sobre A Qualidade De Carne De Peito De Frango. Ciênc. Tecnol. Aliment., Campinas, 24(2): 230235, abr.-jun. 2004.

LAPPE, R. Influencia Da Utilização Do Extrato Hidroalcoolico Da Própolis Sobre O Desenvolvimento De Fungos e Características Físico-Quimicas E Sensoriais Do Salame Tipo Italiano. Santa Maria, RS, Brasil 2004. Dissertação de mestrado. Centro de Ciências Rurais, Programa de Pós-Graduação em Ciência e Tecnologia dos Alimentos.

MENDES, A. A.; KOMIYAMA, C. M. Estratégias de manejo de frangos de corte visando qualidade de carcaça e carne. In: Revista Brasileira de Zootecnia, v. 40, p. 352-357, 2011

PORTO, A. C. S.; TÔRRES, R. C. O.; ILHA, E. C.; LUIZ, M. T. B.; SANT’ANNA E. S. Influência Da Composição Da Salmoura Sobre Os Parâmetros Físico-Sensoriais E Microbiológicos De Filés De Peito De Frango Marinados Por Imersão. B.CEPPA, Curitiba, v. 18, n. 2, p. 141-150, jul./dez. 2000.

RODRIGUES, K. F.; RODRIGUES, P. B.; BRESSAN, M. C.; NAGATA, A. K.; SILVA, J. H. V.; SILVA, E. L. Qualidade da carne de peito de frangos de corte recebendo rações com diferentes relações lisina digestível: proteína bruta. R. Bras. Zootec., v.37, n.6, p.1023-1028, 2008.

SOUZA, X.R.; BRESSAN, M.C.; PÉREZ, J.R.O. et al. Efeitos do grupo genético, sexo e peso ao abate sobre as propriedades físico-químicas da carne de cordeiros em crescimento. Ciência e Tecnologia dos Alimentos, v.24, n.4, p.543-549, 2004.

VENTURINI, K. S.; SARCINELLI, M. F.; SILVA, L. C. Características da Carne de Frango. Universidade Federal do Espírito Santo - UFES Pró-Reitoria de Extensão - P r o g r a m a Institucional de Extensão Boletim Técnico - PIE-UFES:01307 - Editado: 18.08.2007. 